\title{
Strategies to Optimize D rotrecogin alfa (activated) Use: Guidelines and Therapeutic Controversies
}

\begin{abstract}
Henry Cohen, Pharm.D., and Lynda S. Welage, Pharm.D., FCCP
Drotrecogin alfa (activated) is a new agent that may substantially affect the treatment of patients with severe sepsis. Despite its therapeutic promise, treatment with drotrecogin alfa (activated) represents a new challenge for many clinicians and health care centers. Specifically, optimizing the appropriate role for drotrecogin alfa (activated) requires balancing numerous issues, including its efficacy in high-risk patients with its potential for indiscriminate administration. One common approach to minimizing indiscriminate administration of drotrecogin alfa (activated) and maximizing its efficacy while minimizing its toxicity is for hospitals to develop therapeutic guidelines that define how the agent should be used. We outline factors that should be considered when developing drotrecogin alfa (activated) therapy guidelines and address realistic questions that routinely arise in clinical practice regarding the implementation of such guidelines and the administration of this product. In general, the guidelines must facilitate optimization of drug therapy and not be viewed as hurdles to drug therapy. Developing clear guidelines that are based on evidence, outlining a specific process to facilitate optimal therapy, and educating all parties involved are paramount to ensuring that the benefits of therapy are maximized.
\end{abstract}

(Pharmacotherapy 2002;22(12 Pt 2):223S-235S)

\section{OUTLINE}

Factors to Consider in Developing Guidelines

Diagnostic Criteria: Defining Who Should Receive Drotrecogin alfa (activated)

Time Frame for Diagnosis and Administration

Weighing Risks versus Benefits: Identifying

Contraindications or Warnings

Admixture Preparation Considerations

Dilution

Fluid Load

From the Arnold and Marie Schwartz College of Pharmacy and Health Sciences, Long Island University, and the Department of Pharmaceutical Services, Kingsbrook Jewish Medical Center, Brooklyn, New York (Dr. Cohen); and the Department of Clinical Sciences, University of Michigan College of Pharmacy, and the Department of Pharmacy Services, University of Michigan Health System, Ann Arbor, Michigan (Dr. Welage).

Address reprint requests to Henry Cohen, Pharm.D., BCPP, CGP, Kingsbrook Jewish Medical Center, Department of Pharmaceutical Services, 585 Schenectady Avenue, Brooklyn, NY 11203; e-mail: Henry.Cohen@LIU. edu.
Sodium Load

Minimizing Drug Waste

Successful Implementation of the Guidelines

The mortality rate associated with severe sepsis may approach $50 \%$, with an annual cost burden to society of approximately $\$ 17$ billion.1,2 Drotrecogin alfa (activated) (Xigris; Eli Lilly and Company, Indianapolis, IN) is a new agent that may substantially affect the treatment of patients with severe sepsis. The Recombinant Human Activated Protein C Worldwide Evaluation in Severe Sepsis (PROWESS) trial demonstrated an absolute reduction in the risk of death of $6.1 \%{ }^{3}$ On November 21, 2001, drotrecogin alfa (activated) received approval by the United States Food and Drug Administration (FDA) for reducing mortality in adult patients with severe sepsis who have a high risk of death., 5 This is the first drug to receive FDA approval for the management of severe sepsis. 
Despite its therapeutic promise, treatment with drotrecogin alfa (activated) represents a new challenge for many clinicians and health care centers. For example, the acquisition cost of drotrecogin alfa (activated) is substantial and, thus, may have a considerable impact on the hospital pharmacy's drug budget. ${ }^{6}$ Furthermore, based on results of the PROWESS trial, drotrecogin alfa (activated) has been proven to reduce mortality for patients who are at a high risk of death from severe sepsis. ${ }^{3}$ Nonetheless, as in many clinical trials, stringent inclusion and exclusion criteria were used. ${ }^{3}$ Thus, extrapolation of the results to routine clinical practice is somewhat difficult and has led to many therapeutic questions. Specifically, concerns exist regarding its safety in routine clinical practice, as well as its efficacy in less severely ill populations. Moreover, the diagnosis of severe sepsis is somewhat difficult, making the identification of optimal candidates for drotrecogin alfa (activated) therapy a challenge. Optimizing the appropriate administration of drotrecogin alfa (activated) requires a careful balance among numerous issues, including its efficacy in highrisk patients with the potential for indiscriminate administration. One common approach to minimizing indiscriminate administration of drotrecogin alfa (activated) and maximizing its efficacy while minimizing its toxicity is for hospitals to develop therapeutic guidelines that define how the agent should be administered.

Guidelines can take on various forms. Drug use guidelines outline how a given agent should be administered, and treatment guidelines outline how a given disease state should be managed. ${ }^{7}$ In both cases, guidelines are educational tools that can be used as part of the formulary management system. We outline factors that should be considered when developing guidelines for administering drotrecogin alfa (activated) therapy and provide a template for institutions to use when developing their own guidelines (Appendix 1). Moreover, we address several realistic questions that routinely arise in clinical practice regarding the implementation of such guidelines and/or the administration of this product.

As with the development of other drug administration guidelines, all parties who are considered stakeholders must be involved in the development of the guidelines, as this creates buy-in. ${ }^{8}$ Although the specific individuals involved in the development of drotrecogin alfa (activated) administration guidelines will likely vary from institution to institution, a multi- disciplinary approach should be used. In general, intensivists, infectious disease specialists, pulmonologists, surgeons, pharmacists, and nurses should be included in the decision-making process. Others individuals, depending on institutional practices, may be involved in developing the guidelines, such as other specialty physicians, risk management personnel, ethicists, and various administrators, which may include the medical director, chief financial officer, and the chairman of the pharmacy and therapeutics committee. For the guidelines to be used as an effective formulary management tool, the hospital's pharmacy and therapeutics committee should approve the drotrecogin alfa (activated) administration guidelines formally and develop a process for ensuring successful implementation of the guidelines.

Numerous factors should be considered when developing drotrecogin alfa (activated) administration guidelines. In general, the guidelines should identify which patients are candidates for the product and when the product should be administered. In addition, they should outline specific contraindications and/or warnings regarding drotrecogin alfa (activated) therapy in certain circumstances. The committee developing the guidelines should be encouraged to develop additional educational tools that can facilitate appropriate administration, such as dosing guidelines, monitoring guidelines, and drug and severe sepsis monographs. As much as possible, an evidence-based decision-making process should be used to develop the guidelines. ${ }^{8}$ Unfortunately, many questions remain unanswered regarding drotrecogin alfa (activated) therapy, and as a result, clinicians must extrapolate information from other circumstances. The therapeutic questions that may arise in routine clinical practice regarding the administration of this product and/or the implementation of the guidelines represent therapeutic challenges for all clinicians, as no definitive data exist. As science evolves and our understanding of the safety and efficacy of drotrecogin alfa (activated) expands, answers will emerge to these therapeutic challenges. In the meantime, however, all of us are faced with extrapolating data and using our best clinical judgment.

\section{Factors to Consider in Developing Guidelines}

From a simplistic standpoint, when developing guidelines to optimize drug administration, one 
should identify who should receive the agent, when the agent should be administered to optimize success, how the agent should be administered (e.g., dosage, route of administration), who should not receive the agent or in whom one should carefully weigh the potential risks versus benefits, monitoring parameters, and factors that may affect the safety and/or efficacy of the agent. Although a template of drug administration guidelines has been included in Appendix 1, clinicians must understand the issues surrounding each of these decision-making steps, since guidelines at individual institutions may vary depending on interpretation of the available data.

Diagnostic Criteria: Defining Who Should Receive Drotrecogin alfa (activated)

Drotrecogin alfa (activated) is indicated for adult patients with severe sepsis who are at high risk of death. ${ }^{5}$ Intuitively, this statement seems to accurately define who should receive this drug. Unfortunately, on closer examination, many issues need to be considered when developing criteria that determine which patients should receive drotrecogin alfa (activated).

\section{Defining Severe Sepsis: Pitfalls of SIRS Criteria}

The systemic inflammatory response syndrome (SIRS) is defined as a systemic inflammatory response to a variety of clinical insults, manifested by two or more of the following: temperature higher than $38^{\circ} \mathrm{C}$ or lower than $36^{\circ} \mathrm{C}$, heart rate greater than 90 beats/minute, respiratory rate greater than 20 breaths/minute or partial pressure of carbon dioxide $\left(\mathrm{PCO}_{2}\right)$ less than $32 \mathrm{~mm} \mathrm{Hg}$, or a white blood cell count greater than $12 \times 10^{3} / \mathrm{mm}^{3}$ or less than $4 \times$ $10^{3} / \mathrm{mm}^{3}$ or greater than $10 \%$ immature forms (bands). 9,10 Severe sepsis is defined as the systemic inflammatory response to infection, with the presence of organ dysfunction, hypoperfusion, or hypotension. ${ }^{9,10}$ The PROWESS trial used modified and more stringent SIRS criteria; the study required patients to meet at least three (rather than two) SIRS criteria for diagnosis. $^{3}$ Although the modified SIRS criteria may be more sensitive or specific, this approach has not been validated. In addition, SIRS criteria regarding core temperature, heart rate, and white blood cell count may inadvertently exclude certain patients who are in fact septic. In the geriatric population, in which severe sepsis is most prevalent, a core temperature of $38^{\circ} \mathrm{C}$ or greater $\left(\geq 100.4^{\circ} \mathrm{F}\right)$ may not be prominent. ${ }^{11}$ Many elderly patients, who have lower than normal baseline body temperatures, experience a spike in response to infection that does not exceed $38^{\circ} \mathrm{C}$. In some cases, the criterion of a heart rate of 90 beats/minute or greater may not be met owing to disease- (e.g., hypothyroidism) and drug-induced suppression of heart rate. Occasionally, cachectic elderly patients with comorbid conditions such as diabetes and chronic obstructive pulmonary disease are unable to mount an infection-induced increase in white blood cells that exceeds $12 \times 10^{3} / \mathrm{mm}^{3} .12 \mathrm{In}$ addition, although a differential showing greater than $10 \%$ bands is one criterion for SIRS, because of the lack of laboratory sensitivity and specificity in determining the immature band count, many institutions no longer routinely perform this test as part of a complete blood count. ${ }^{13}$

\section{Defining High Risk of Death}

As previously stated, the FDA has approved drotrecogin alfa (activated) for the reduction of mortality in adult patients with severe sepsis (sepsis associated with acute organ dysfunction) who have a high risk of death (e.g., as determined by the Acute Physiology and Chronic Health Evaluation [APACHE] II scoring system). ${ }^{5}$ In the PROWESS trial, the APACHE II scores were calculated from physiologic and laboratory data obtained within the 24-hour period immediately before drotrecogin alfa (activated) administration, irrespective of the preceding length of stay in the intensive care unit. ${ }^{3}$ The highest score for each component of the APACHE II was used for data analysis. The mean APACHE II score in the patients who received drotrecogin alfa (activated) was $25 \pm 7.8$. Patients with APACHE II scores in the first and second quartiles (scores 3-24) did not have an absolute mortality reduction compared with the placebo group. However, patients with APACHE II scores in the third and fourth quartiles (scores 25-53) achieved a 13\% absolute mortality difference relative to the placebo group. The manufacturer indicates that APACHE II scores were most effective in determining the patients who were most likely to benefit from drotrecogin alfa (activated) therapy. ${ }^{5}$ However, the manufacturer also mentions that other indicators of the severity of illness, such as number of organ failures, were predictive in determining the patients who were most likely to benefit from drotrecogin alfa (activated) therapy. 
Patients with one, two, three, and four or more organ failures experienced absolute reductions in mortality of $2 \%, 5 \%, 8 \%$, and $11 \%$, respectively. ${ }^{5}$

When developing guidelines for drotrecogin alfa (activated), one must decide how the institution will identify patients who are at high risk of death from severe sepsis. The two most common approaches involve determining APACHE II scores or number of organ failures. The APACHE II scoring process can be highly subjective, error prone, and labor and time intensive. ${ }^{14}$ Determining who will perform the APACHE II scoring and when and how often it will be performed, and deciding how to interpret divergent scoring by different clinicians may be an arduous and unrealistic task. For example, an APACHE II score of 23 versus 25 may be the deciding factor on who will receive therapy. N ote that the APACHE II scoring system was not validated to this degree of sensitivity. For each 5point increase in APACHE II score, there is a significant increase in the risk of death. ${ }^{15}$ However, attempting to distinguish between patients whose scores are within 4 points of each other is nebulous. ${ }^{15}$ Therefore, using the number of organ failures as the absolute criterion for determining candidates for drotrecogin alfa (activated) therapy instead of the APACHE II scoring system may be a more practical approach.

To maximize benefit and curtail drug acquisition costs, many institutions use two organ failures as the minimal criterion, although some institutions have opted to use one organ failure. The decision to establish two organ failures as the minimal criterion for drotrecogin alfa (activated) therapy often relates to the fact that in the PROWESS trial patients with two organ failures ( $75 \%$ of the trial population) had an absolute reduction in the risk of death of $5 \%$, which is similar to the overall results experienced in the trial (i.e., $6 \%$ absolute risk reduction). Thus, although not perfect, the number of organ systems failing becomes a surrogate for severity of illness. This approach may be more pragmatic, particularly when making therapeutic decisions regarding administration of drotrecogin alfa (activated) at the bedside. However, the type of organ dysfunction must be identified to be considered as part of the criterion.

In the PROWESS trial, drotrecogin alfa (activated) was administered to patients with severe sepsis and at least one associated acute organ dysfunction. ${ }^{3}$ Acute organ dysfunction included any one of the following five criteria: cardiovascular, renal, respiratory, or hematologic dysfunction, or unexplained metabolic acidosis. Of note, several other acute organ dysfunctions were not part of the PROWESS criteria, including hepatic (e.g., jaundice, elevated liver enzymes), central nervous system (e.g., psychosis, delirium, coma), endocrine (e.g., hyperglycemia, hypertriglyceridemia), and gastrointestinal (e.g., bleeding, perforation, ileus). The drotrecogin alfa (activated) guidelines depicted in Appendix 1 include only the organ dysfunctions from the PROWESS trial.

\section{Time Frame for Diagnosis and Administration}

In the pivotal trial that spawned the approval of drotrecogin alfa (activated) (the PROWESS trial), patients were eligible to receive drotrecogin alfa (activated) if they met the criteria for severe sepsis that lasted no longer than 24 hours from the time of screening. ${ }^{3}$ Subsequently, drotrecogin alfa (activated) therapy had to be started within 24 hours after they met the inclusion criteria. The mean time from first organ dysfunction to the start of drotrecogin alfa (activated) therapy was $17.4 \pm 9.1$ hours. Theoretically, the methodology in the PROWESS trial permitted a maximum of a 48-hour window from screening and severe sepsis onset to drug administration. Based on the data from the PROWESS study, guidelines regarding drotrecogin alfa (activated) therapy should state clearly the time frame for establishing the required diagnostic criteria and administering the product (i.e., meeting diagnostic criteria within 48 hrs of drug administration). Although some clinicians may take the approach of waiting until nearing the 48-hour deadline to administer the agent, this approach is ill advised and not recommended because the sepsis cascade is a vicious and relentless cycle with high mortality. Similarly, in cases in which retrospective assessment suggests that the severe sepsis developed several days previously ( $>48 \mathrm{hrs}$ ), administration of drotrecogin alfa (activated) is not advised because no data exist to support its efficacy. The latter situation (> $48 \mathrm{hrs}$ ), however, often represents an ethical controversy because although no data exist to support the efficacy of drotrecogin alfa (activated), there is no therapeutic alternative. Although individual situations may be managed differently, the committee developing drotrecogin alfa (activated) guidelines should delineate the general approach that will be recommended to practitioners. 
Weighing Risks versus Benefits: I dentifying Contraindications or Warnings

In addition to identifying who should receive drotrecogin alfa (activated), the drug administration guidelines should identify who should not receive the agent and identify populations in whom the decision to administer drotrecogin alfa (activated) must be weighed carefully against its risks. These decisions can be classified broadly as identifying contraindications and/or warnings involving drotrecogin alfa (activated) in certain populations. In general, these situations may affect the patient's safety, or no data are available to support the efficacy. Because drotrecogin alfa (activated) is a recombinant form of the body's natural anticoagulant, activated protein C, it may increase the risk of serious bleeding events. Owing to the risk of bleeding and the associated high risk of death or significant morbidity, the manufacturer states that drotrecogin alfa (activated) is contraindicated in patients with active bleeding, recent (within $3 \mathrm{mo}$ ) hemorrhagic stroke, recent (within $2 \mathrm{mo}$ ) intracranial or intraspinal surgery or severe head trauma, trauma with an increased risk of life-threatening bleeding, presence of an epidural catheter or intracranial neoplasm or mass lesion, or evidence of cerebral herniation. ${ }^{5}$ In addition, drotrecogin alfa (activated) is contraindicated in patients with known hypersensitivity to the drug or any component of it. ${ }^{5}$ However, many patients who were at risk for potential bleeding were excluded from the pivotal trial; therefore, safety and efficacy data are lacking for these patients. ${ }^{3}$ Specifically, in the PROWESS trial, to minimize the risk of bleeding, the exclusion criteria for patients who may be at a higher risk of bleeding was comprehensive and included many scenarios that are not included in the manufacturer's contraindications. ${ }^{3,5}$

Because of the risk of bleeding, some clinicians have opted to use the PROWESS exclusion criteria in patients at an increased risk of bleeding as absolute contraindications. The guidelines depicted in Appendix 1 list the PROWESS exclusion criteria, similar to the FDAapproved manufacturer's labeling of warnings, requiring the clinician to evaluate the anticipated benefits of drotrecogin alfa (activated) carefully against the risks. The final choice in administering drotrecogin alfa (activated) despite one or more bleeding risks is at the clinician's discretion. In the PROWESS trial, patients were excluded for specific criteria including a futile diagnosis, increased risk of bleeding, and a known hypercoagulable condition (Appendix 1 , section IV) ${ }^{3}$; however, these specific criteria are not mentioned in the FDA-approved manufacturer's labeling. ${ }^{5}$ Hence, the clinician must weigh the benefits of drotrecogin alfa (activated) therapy carefully against the risks in patients with these scenarios.

Some of the PROWESS trial exclusionary criteria may not be clinically relevant. For example, although patients weighing more than $135 \mathrm{~kg}$ were excluded from the PROWESS trial, this was done only to ensure an adequate supply of the drug. Nevertheless, a paucity of reported pharmacokinetic, efficacy, and safety data exists in patients with severe sepsis who weigh more than $135 \mathrm{~kg}$. Pharmacokinetics are linear from $3-133 \mathrm{~kg}$ at the recommended dosage of 24 $\mu \mathrm{g} / \mathrm{kg} / \mathrm{hour}$.

Alternatively, some of the PROWESS trial exclusionary criteria may be clinically relevant, such as chronic renal failure requiring hemodialysis or peritoneal dialysis because of disease-induced decreased platelet aggregation and an inherent risk of bleeding. Indeed, a retrospective analysis of the Efficacy and Safety of Subcutaneous Enoxaparin in Non-Q-Wave Coronary Events (ESSENCE) and Thrombolysis in Myocardial Infarction (TIMI) 11B trials found that the administration of heparin or lowmolecular-weight heparin in patients with chronic renal failure was associated with a 6 -fold increase in the occurrence of serious bleeding events and a trend toward an increase in composite end points (death, myocardial infarction, and recurrent angina). ${ }^{16}$ Since data regarding drotrecogin alfa (activated)'s efficacy and risk of bleeding in patients with chronic renal failure who are receiving dialysis treatments have not been studied, the potential risks and benefits of therapy must be weighed carefully in these patients. Patients with acute renal failure requiring dialysis were excluded in the PROWESS trial. Finally, known hypercoagulable conditions such as resistance to activated protein C may blunt or eliminate the efficacy of drotrecogin alfa (activated). In the PROWESS trial, however, patients who were not protein C deficient (95 patients) realized similar mortality benefits compared with those who were protein C deficient (605 patients). ${ }^{3}$ Data regarding the efficacy of drotrecogin alfa (activated) in patients with known hypercoagulable states do not exist. One strategy for dealing with these situations as part of the guidelines and ordering process, as 
outlined in Appendix 1, is to require the clinician to acknowledge such situations (i.e., the PROWESS exclusion criteria not mentioned in the FDA-approved product labeling) and determine whether there is benefit to drotrecogin alfa (activated) therapy relative to the risk of bleeding and/or high cost.

\section{Placing the Risk of Bleeding into Perspective}

During the 96-hour infusion period in the PROWESS trial, the frequency of serious bleeding events was $2.4 \%$ with drotrecogin alfa (activated) and $1 \%$ with placebo, which is both clinically and statistically significant $(p=0.024){ }^{3}$ Conversely, during the 28-day study observation period, the frequency of serious bleeding events was 3.5\% with drotrecogin alfa (activated) and $2 \%$ with placebo $(p=0.060) .^{3}$ In the PROWESS trial, serious bleeding was defined as any intracranial hemorrhage, any life-threatening bleeding, any bleeding event classified as serious by the investigator, or any bleeding that required administration of more than 3 units of blood on 2 consecutive days. Despite the risk of serious bleeding events, benefits of drotrecogin alfa (activated) therapy were realized. Indeed, many trials for acute coronary syndromes in which several agents that alter the coagulation profile (e.g., aspirin, heparin, low-molecular-weight heparins, glycoprotein IIb-IIla inhibitors) were administered yielded statistically significant benefits despite the added occurrence of serious bleeding events. Theoretically, administering drotrecogin alfa (activated) in patients with a predisposing bleeding risk may increase the frequency of serious bleeding events. Whether the benefits of administering drotrecogin alfa (activated) in these settings will outweigh the risk has not been studied. Patients with overt disseminated intravascular coagulopathy had an absolute reduction of mortality of $23 \%$ yet no increase in bleeding. One noteworthy point is that in the PROWESS trial the reductions in mortality and the frequency of a serious bleeding event were similar in patients receiving prophylactic dosages of heparin ( $\leq 15,000 \mathrm{U} /$ day) or no heparin $(24.92 \%$ vs $24.07 \%$ and $2.37 \%$ vs $2.31 \%$, respectively). ${ }^{3}$ Serious bleeding with drotrecogin alfa (activated) therapy occurred predominantly during infusion.

From the anticoagulant literature, the risk of bleeding is related to the intensity of anticoagulation therapy or anticoagulant response, patient characteristics, concomitant therapy, and duration of anticoagulant administration. ${ }^{17}$ Although the definition of major bleeding varies slightly among anticoagulant trials and is different than that used in the PROWESS trial, the American College of Chest Physicians (ACCP) defines bleeding as major if it was intracranial or retroperitoneal or if it led directly to death or resulted in hospitalization or transfusion. ${ }^{17,18}$ With use of the ACCP definition, the rates of major bleeding associated with intravenous unfractionated heparin were $0-7 \%$, with the rates of fatal bleeding being $0-2 \% .{ }^{18}$ For low-molecular-weight heparin, the rates of major bleeding were reported to be $0-3 \%$, with the rates of fatal bleeding ranging from $0-0.8 \% .{ }^{17}$ These data place into clinical perspective the risk of major bleeding for drotrecogin alfa (activated) relative to that of other agents that alter the coagulation profile and are commonly given to critically ill patients. The risk of serious bleeding as identified in the PROWESS study is similar or lower than the risk commonly observed with therapeutic heparin; however, one must be cognizant that the definitions for major bleeding were significantly different. ${ }^{3,17}$ The rates of intracranial hemorrhage observed in the PROWESS trial and open-label studies $(0.2-1 \%)$ are similar to that observed during long-term warfarin therapy $(0.2-1.8 \%))^{3,17}$ Extrapolating Lessons Learned with Other
Anticoagulants

The rate of bleeding associated with heparin is influenced by the dosage of heparin and the subsequent anticoagulant response. ${ }^{17}$ Bleeding is more likely to occur when an in vitro test of response (such as activated partial thromboplastin time [aPTT]) is prolonged excessively. However, bleeding can occur even when the in vitro test of response is in the therapeutic range. In addition, drotrecogin alfa (activated) may variably prolong aPTT, and thus aPTT cannot be used reliably to assess the degree of coagulation or coagulopathy or to predict bleeding risk. ${ }^{5}$ The effect of drotrecogin alfa (activated) on aPTT depends in part on how quickly the sample is assayed. Patients with severe sepsis often have a coagulopathy (independent of drug administration) that is associated with prolongation of aPTT and prothrombin time. Prothrombin time is not affected by drotrecogin alfa (activated) and can be used to monitor the patient's underlying coagulopathy. 
There is also evidence from the anticoagulation literature that comorbid conditions such as recent surgery, recent trauma, or concomitant antiplatelet therapy increase the risk of bleeding. ${ }^{17}$ Although these high bleeding risk situations can be considered as either warnings or contraindications to drotrecogin alfa (activated) therapy, in the clinical arena one often is faced with therapeutic challenges. For example, patients with severe thrombocytopenia are at an increased risk of bleeding. The PROWESS trial excluded patients with platelet counts less than $30 \times 10^{3} / \mathrm{mm}^{3}$. However, the following question likely will arise: Should a patient with thrombocytopenia and severe sepsis receive drotrecogin alfa (activated)? Since no direct evidence is available to quantify the additional bleeding risk of administering drotrecogin alfa (activated) to a patient with a low platelet count, one must weigh the risks and benefits of this situation carefully. However, patients receiving drotrecogin alfa (activated) who had baseline platelet counts less than $50 \mathrm{x}$ $10^{3} / \mathrm{mm}^{3}$ had a lower mortality rate compared with that of the placebo group ( $25 \%$ vs $63 \%$, respectively). ${ }^{19}$ Similarly, in the PROWESS study, platelet counts decreased to less than $30 \mathrm{x}$ $10^{3} / \mathrm{mm}^{3}$ within the first 5 study days in 34 patients receiving either drotrecogin alfa (activated) or placebo. The patients receiving drotrecogin alfa (activated) had a lower mortality rate $(33 \%)$ compared with that of the placebo group (84\%). 19

Another common clinical scenario not studied in the PROWESS trial that is encountered in clinical practice poses the following question: Should antiplatelet agents, with the exception of aspirin at dosages less than $650 \mathrm{mg} /$ day, be discontinued when drotrecogin alfa (activated) is started or do antiplatelet agents preclude administration of drotrecogin alfa (activated)? Although the risk of bleeding associated with heparin increases with concomitant aspirin administration, this combination commonly is given in the initial treatment of acute coronary artery syndromes, with benefit and without serious bleeding. ${ }^{17}$ Furthermore, because the effects of aspirin persist ( 7 days) for longer than the maximum 4-day infusion time of drotrecogin alfa (activated), discontinuation of aspirin before drotrecogin alfa (activated) may not minimize the risk of bleeding. Similarly, although the risk of heparin-associated bleeding increases with concomitant thrombolytics or glycoprotein IIbIII a antagonists, these agents frequently are coadministered. ${ }^{17}$ Extrapolating data from heparin studies enables identification of situations that may place patients receiving drotrecogin alfa (activated) at a greater risk of bleeding. However, such situations in most cases should not be viewed as absolute contraindications. Similar to the situation with other anticoagulants (heparin, warfarin), the individual risks and potential benefits must be weighed carefully for each patient.

\section{Admixture Preparation Considerations}

The recommended dosage regimen for drotrecogin alfa (activated) is $24 \mu \mathrm{g} / \mathrm{kg} / \mathrm{hour}$ to be given as a continuous intravenous infusion for 96 hours. 5,20 The dosage should be based on the patient's total body weight at the start of therapy. To minimize administration errors and drug waste, the storage, preparation, and labeling of drotrecogin alfa (activated) should be under the strict supervision of a pharmacist. The reconstitution and admixture of drotrecogin alfa (activated) must use an aseptic technique. In institutions where 24-hour pharmacy services are not available, an alternative plan to prepare the agent should be in place (e.g., on-call pharmacist). Drotrecogin alfa (activated) reconstitution and administration guidelines are depicted in Appendix 2.

\section{Dilution}

When using an intravenous infusion pump, drotrecogin alfa (activated) admixtures must be reconstituted with $0.9 \%$ sodium chloride injection (United States Pharmacopeia), typically to a final concentration of $100-200 \mu \mathrm{g} / \mathrm{ml} .^{5,20}$ Drotrecogin alfa (activated) cannot be administered undiluted or using the intravenous push method. When administering low concentrations at low flow rates (i.e., $<200$ $\mu \mathrm{g} / \mathrm{ml}$ at $<5 \mathrm{ml} / \mathrm{hr}$ ), it is recommended that the infusion set be primed for approximately 15 minutes at a flow rate of $5 \mathrm{ml} /$ hour. $^{5,20}$

\section{Fluid Load}

Occasionally, critically ill patients have a fluid and sodium restriction. To minimize the amount of admixture fluid used in these rare instances, we suggest admixing drotrecogin alfa (activated) in the most concentrated solutions allowable. The dosing guidelines in Appendix 3 are based exclusively on the administration of drotrecogin alfa (activated) $200 \mu \mathrm{g} / \mathrm{ml}$ by an infusion pump. 
For example, a patient weighing $70 \mathrm{~kg}$ requires drotrecogin alfa (activated) $10 \mathrm{mg}$ every 6 hours (40 mg/day). At a concentration of $100 \mu \mathrm{g} / \mathrm{ml}$, each 10-mg dose would require $100 \mathrm{ml}$, which would result in $400 \mathrm{ml} /$ day of normal saline. At a concentration of $200 \mu \mathrm{g} / \mathrm{ml}$, each $10-\mathrm{mg}$ dose would require $50 \mathrm{ml}$, totaling $200 \mathrm{ml} /$ day of normal saline. The net savings of $200 \mathrm{ml} /$ day of normal saline may be significant in patients requiring several drugs in large volume admixtures. Furthermore, when using a syringe pump to administer drotrecogin alfa (activated), concentrated solutions of up to $1000 \mu \mathrm{g} / \mathrm{ml}$ are allowable and greater fluid savings are realized. Although not all patients will require a concentrated solution, using several different concentrations is error prone, and a standard concentration is recommended. A drotrecogin alfa (activated) dosing chart with infusion rates $(\mathrm{ml} / \mathrm{hr})$ based on dosage and the patient's weight, using a drug concentration of $200 \mu \mathrm{g} / \mathrm{ml}$, is provided in Appendix 3.

\section{Sodium Load}

High sodium loads can be detrimental in certain critically ill patients (e.g., patients with pulmonary edema, renal failure, cirrhosis with ascites, or chronic heart failure). In these instances, sodium chloride intake should be restricted to no more than 1-2 g/day. Drotrecogin alfa (activated) 5- and $20-\mathrm{mg}$ vials contain $40.3 \mathrm{mg}$ and $158.1 \mathrm{mg}$ of sodium chloride, respectively. ${ }^{5}$ A patient weighing $70 \mathrm{~kg}$ who receives drotrecogin alfa (activated) at a dosage of $10 \mathrm{mg} / 100 \mathrm{ml}$ every 6 hours, using a concentration of $100 \mu \mathrm{g} / \mathrm{ml}$ in normal saline will add a sodium load of $1738 \mathrm{mg}$ ( $322 \mathrm{mg}$ from drug and $1416 \mathrm{mg}$ from normal saline). In the critical care setting where high sodium load-containing drugs (e.g., metronidazole, piperacillin, and ticarcillin) are administered routinely, the cumulative sodium load can be significant. One strategy to minimize sodium load is to admix drotrecogin alfa (activated) with dextrose solutions rather than sodium chloride. However, because stability data do not exist, this practice is not recommended. Clinicians should be cognizant of drotrecogin alfa (activated)'s sodium load and should consider concentrated solutions in sodium-restricted patients.

\section{Minimizing Drug Waste}

To maximize drotrecogin alfa (activated) cost savings by minimizing waste, it is permissible to develop preparation guidelines that are based on patients' actual body weight, that use multiple dosing intervals such as every 6-, 8-, and 12-hour continuous infusions, and by purchasing 5-mg vials rather than $20-\mathrm{mg}$ vials. Unfortunately, no one dosage interval is cost-effective for all patient weights. For example, at a dosage of 24 $\mu \mathrm{g} / \mathrm{kg} / \mathrm{hour}$, a patient weighing $70 \mathrm{~kg}$ will require drotrecogin alfa (activated) $40 \mathrm{mg} /$ day. A 6-hour interval of $10 \mathrm{mg}$ will require 2 vials/dose, 8 vials/day, and 32 vials for the 96-hour treatment-at a cost of $\$ 6720$. Comparatively, for the same patient weighing $70 \mathrm{~kg}$, an 8-hour interval of $13.44 \mathrm{mg}$ will require 2.5 vials/dose, 9 vials/day, and 36 vials for the 96-hour treatment-at a cost of $\$ 7560$. Owing to the drug waste in the every-8-hour regimen compared with no waste in the every-6-hour regimen, a cost savings of $\$ 840 /$ patient can be realized. Although, the use of different dosing intervals will limit drug waste and realize cost savings, a higher risk of drug error may prevail.

One practical question that often arises is whether the milligram dose of drotrecogin alfa (activated) can be rounded off? This question arises in part because of the agent's limited stability, availability in only 5 - and $20-\mathrm{mg}$ vials, and acquisition cost. For example, a patient weighing $90 \mathrm{~kg}$ would require $25.9 \mathrm{mg}$ of drotrecogin alfa (activated) over a 12-hour period. Since drotrecogin alfa (activated) is available in 20-mg vials, the question arises whether to round down the dose to $20 \mathrm{mg}$ administered as a continuous infusion over 12 hours (i.e., $18.5 \mu \mathrm{g} / \mathrm{kg} / \mathrm{hr}$ ) or to alter the dosing interval (e.g., $24 \mu \mathrm{g} / \mathrm{kg} / \mathrm{hr}$ for $8 \mathrm{hrs}=17.3$ $\mathrm{mg} /$ dose of drotrecogin alfa [activated]). Although the former approach of rounding down the dose of drotrecogin alfa (activated) may appear appealing, the phase II dose-ranging study demonstrated that when the dose was decreased from $24 \mu \mathrm{g} / \mathrm{kg} / \mathrm{hour}$ to $18 \mu \mathrm{g} / \mathrm{kg} /$ hour, the effect on the clotting and inflammatory markers waned. ${ }^{21}$ However, the effect of drotrecogin alfa (activated) on the clotting and inflammatory markers increased as the dose increased from 24 to $30 \mu \mathrm{g} / \mathrm{kg} /$ hour. From this information, we can infer that decreasing the dosage to a value below the minimum dosage that was effective in decreasing mortality is not justifiable.

\section{Successful Implementation of the Guidelines}

Clearly, a multitude of factors must be considered when developing drotrecogin alfa 
(activated) administration guidelines. Although the available evidence must be used to support the decision-making process, this issue should not be evaluated in a vacuum, but all the evidence and relevant data should be considered. The available evidence regarding drotrecogin alfa (activated) should be integrated with current data for other products administered in the intensive care unit in order to develop a guide to realistic drotrecogin alfa (activated) therapy that optimizes potential outcomes, by targeting patients who are likely to benefit from the agent while taking into consideration the risk of bleeding.

Successful implementation of drotrecogin alfa (activated) administration guidelines requires education of all the physicians, pharmacists, and nurses involved in the management of sepsis. Everyone should understand both the guidelines and the process used to prescribe the drug. Because of the complexity of the disease state and the drug administration guidelines, in addition to the agent's high acquisition cost, many institutions have elected to designate authorized prescribers. If this approach is chosen as part of the implementation process, the list of authorized prescribers must be identified and a process for obtaining the agent at anytime must be outlined, despite the potential availability of the authorized prescriber (e.g., in the middle of the night). The authorized prescriber or gatekeeper must have a thorough understanding of the management of severe sepsis and the administration guidelines for drotrecogin alfa (activated).

One step that may facilitate implementation of the guidelines is the use of an order form specifically designed for prescribing drotrecogin alfa (activated), as depicted in Appendix 1. Such tools can serve many purposes, including educating clinicians on drotrecogin alfa (activated) guidelines, aiding the prescribing process (e.g., checklists), and quality assurance. After the guidelines are implemented, periodic review of the process and appropriate administration of drotrecogin alfa (activated) should be evaluated in a quality improvement manner.

The drotrecogin alfa (activated) guidelines are the first step in optimizing the management of sepsis. Although many institutions may view such guidelines as a process to control drug administration, one should target optimizing the management of severe sepsis and develop other aids that will address additional aspects of the management of sepsis. In general, the guidelines must facilitate optimization of drug therapy and should not be viewed as overwhelming obstacles to drug therapy. Developing clear guidelines that are based on evidence, outlining a specific process to facilitate optimization of therapy, and educating all parties involved are tantamount to ensuring that the benefits of drotrecogin alfa (activated) are maximized. Clinicians should recognize these guidelines as an attempt to facilitate appropriate prescribing and not as a barrier to drug therapy.

\section{References}

1. Natanson C, Sposito CJ, Banks SM. The sirens' song of confirmatory sepsis trials. Crit Care Med 1998;26:1927-31.

2. Angus DC, Linde-Zwirble WT, Lidicker J. Epidemiology of severe sepsis in the United States: analysis of incidence, outcome, and associated costs of care. C rit Care Med 2001;29:1303-10.

3. Bernard GR, Vincent JL, Laterre PF, et al, for the Recombinant Human Activated Protein C Worldwide Evaluation in Severe Sepsis (PROWESS) Study Group. Efficacy and safety of recombinant human activated protein $\mathrm{C}$ for severe sepsis. $\mathrm{N}$ Engl J Med 2001;344:699-709.

4. U.S. Food and Drug Administration. Product approval information. Center for Biologics Evaluation and Research page. Available from www.fda.gov/cber/approvltr/ droteli11201L.pdf. Accessed September 3, 2002.

5. Eli Lilly and Company. Xigris (drotrecogin alfa [activated]) package insert. Indianapolis, IN; 2001.

6. Cohen HE, ed. Drug topics red book. Montvale, NJ: Medical Economics Company, 2002.

7. American Society of Health-System Pharmacists. ASHP guidelines for formulary system management. Am J Health-Syst Pharm 1992;49:648-52.

8. Moore SR. Pharmacy implications of clinical guideline development. Am J Health-Syst Pharm 1992;49:1763-4.

9. Bone RC, Balk RA, Cerra FB, et al. Definitions for sepsis and organ failure and guidelines for the use of innovative therapies in sepsis. The ACCP/SCCM consensus conference committee. American College of Chest Physicians/Society of Critical Care Medicine. Chest 1992;101:1644-55.

10. Balk RA. Severe sepsis and septic shock: definitions, epidemiology and clinical manifestations. Crit Care Clin 2000;16:179-92.

11. Castle SC, Norman DC, Yeh M, Miller D, Yoshikawa T. Fever response in elderly nursing home residents: are the older truly colder? J Am Geriatr Soc 1991:39:853-7.

12. Swift C G. Pharmacodynamics: changes in homeostatic mechanisms, receptor and target organ sensitivity in the elderly. Br Med Bull 1990;46:36-52.

13. Banez EI. Hematologic response to acute inflammation: the band neutrophil revisited. Tex Med 1990;86:26-8.

14. Civetta JM, Hudson-Civetta JA, Nelson LD. Evaluation of APACHE II for cost containment and quality assurance. Ann Surg 1990;212:266-74.

15. Knaus WA, Draper EA, Wagner DP, Zimmerman JE. APACHE II: a severity of disease classification system. Crit Care Med $1985 ; 13: 818-29$.

16. Inverso SM, Cohen M, Antman EM, Spinler SA. Safety and efficacy of unfractionated heparin versus enoxaparin in obese patients and patients with severe renal impairment: analysis from the ESSENCE and TIMI 11B studies [abstr]. J Am Coll Card 2001;37(suppl A):A365.

17. Levine MN, Raskob G, Landefeld S, Kearon C. Hemorrhagic complications of anticoagulant treatment. Chest 2001;119: S108-21. 
18. Fragmin and Fast Revascularization During Instability in Coronary Artery Disease (FRISC II) Investigators. Long term low molecular mass heparin in unstable coronary artery disease: FRISC II prospective randomized multicenter study. Lancet 1999;354:701-7.

19. U.S. Food and Drug Administration. Drotrecogin alfa (activated) slide presentation presented to the Anti-Infective Advisory Committee, October 16, 2001. Available from
www.fda.gov/ohrms/dockets/ac/01/slides/3793s1_01_LillyCORE. Accessed September 3, 2002.

20. Eli Lilly and Company. Xigris ${ }^{T M}$ dosing tools. Available from www.aboutxigris.com/dose_tools.shtml. Accessed September 3, 2002.

21. Bernard GR, Ely EW, Wright TJ, et al. Safety and dose relationship of recombinant human activated protein $C$ for coagulopathy in severe sepsis. Crit Care M ed 2001;29:2051-9.

\section{Appendix 1. Drotrecogin alfa (activated) (Xigris) Order Form}

The following criteria for drotrecogin alfa (activated) therapy are based on the Recombinant Human Activated Protein C Worldwide Evaluation in Severe Sepsis (PROWESS) study inclusion and exclusion criteria, and U.S. Food and Drug Administration (FDA) guidelines for patients who develop sepsis with sepsis-induced organ dysfunction. Once the order form is completed and all criteria are met and approved by the designated physician, there is a 48-hour window in which drotrecogin alfa (activated) should be administered.

I. Drotrecogin alfa (activated) is indicated for reducing mortality in adult patients with severe sepsis, defined as a known or suspected infection, who meet the criteria for the modified systemic inflammatory response syndrome (SIRS), have at least two organ or system dysfunctions, and have a high risk of death.

A. Patient has a known or suspected infection, defined as one or more of the following:

$\square$ Positive culture.

White blood cells in a normally sterile body fluid.

$\square$ Perforated viscus.

Radiographic evidence of pneumonia along with purulent sputum.

A syndrome associated with a high risk of infection (e.g., ascending cholangitis).

B. Patient has modified SIRS, defined as three or more of the following signs:

口 Core temperature of $\geq 38^{\circ} \mathrm{C}\left(\geq 100.4^{\circ} \mathrm{F}\right)$ or $\leq 36^{\circ} \mathrm{C}\left(\leq 96.8^{\circ} \mathrm{F}\right)$.

- Heart rate of $\geq 90$ beats/minute except in patients with a medical condition known to increase the heart rate (e.g., dysrhythmias, hyperthyroidism, chronic heart failure, anemia) or in those receiving treatment that would prevent tachycardia (e.g., $\beta$-blockers, verapamil, diltiazem, $\alpha_{2}$ agonists [clonidine, methyldopa, guanfacine, guanabenz], digoxin, antidysrhythmics, opioids, carbamazepine [in those aged $\geq 50 \mathrm{yrs}]$ ).

- Respiratory rate of $\geq 20$ breaths/minute or a partial pressure of carbon dioxide $\left(\mathrm{PCO}_{2}\right)$ of $\leq 32 \mathrm{~mm} \mathrm{Hg}$, or mechanical ventilation for an acute respiratory process.

$\square$ White blood cell count of $\geq 12 \times 10^{3} / \mathrm{mm}^{3}$ or $\leq 4 \times 10^{3} / \mathrm{mm}^{3}$, or a differential showing $>10 \%$ bands.

C. Patient has evidence of organ dysfunction, defined as two or more of the following:

$\square$ Cardiovascular (one or more of the following):

$\square$ Arterial systolic blood pressure (SBP) $\leq 90 \mathrm{~mm} \mathrm{Hg}$ or mean arterial pressure (MAP) of $\leq 70 \mathrm{~mm} \mathrm{Hg}$ for at least 1 hour despite adequate fluid resuscitation or adequate intravascular volume status.

$\square$ Vasopressor therapy in an attempt to maintain SBP at $\geq 90 \mathrm{~mm} \mathrm{Hg}$ or M AP at $\geq 70 \mathrm{~mm} \mathrm{Hg}$.

$\square$ Renal:

$\square$ Urine output $<0.5 \mathrm{ml} / \mathrm{kg} / \mathrm{hour}$ for at least 1 hour despite adequate fluid resuscitation.

$\square$ Respiratory (one or more of the following):

$\square$ Ratio of partial pressure of oxygen:fraction of inspired oxygen $\left(\mathrm{PaO}_{2}: \mathrm{FlO}_{2}\right) \leq 250$ in the presence of other organ dysfunction.

- Hematologic (one or more of the following):

- Platelet count $<80 \times 10^{3} / \mathrm{mm}^{3}$ in the preceding 3 days.

Platelet count reduction by $\geq 50 \%$ in the preceding 3 days.

$\square$ Unexplained metabolic acidosis (one or more of the following):

$\checkmark \mathrm{pH} \leq 7.3$ or base deficit $\geq 5 \mathrm{mmol} / \mathrm{L}$.

$\square$ Base deficit $\geq 5 \mathrm{mmol} / \mathrm{L}$ along with plasma lactate level $>1.5$ times the upper limit of normal.

II. Drotrecogin alfa (activated) increases the risk of bleeding. According to the Xigris manufacturer's information, the drug is contraindicated in clinical scenarios in which bleeding can be associated with a high risk of morbidity or mortality.

Absolute contraindications, defined as one or more of the following:

$\square$ Active internal bleeding.

- Hemorrhagic stroke within the past 3 months.

Intracranial or intraspinal surgery or severe head trauma within the past 2 months.

$\square$ Trauma with an increased risk of life-threatening bleeding.

$\square$ Presence of an epidural catheter.

- Intracranial neoplasm or mass lesion or evidence of cerebral herniation.

$\square$ Known sensitivity to drotrecogin alfa (activated) or any component of this product. 


\section{Appendix 1. Drotrecogin alfa (activated) (Xigris) Order Form (continued)}

III. The most common serious adverse effect associated with drotrecogin alfa (activated) is bleeding. Patients with clinical scenarios that may increase the risk of bleeding were excluded from the PROWESS trial; however, the Xigris manufacturer's information does not list these scenarios as contraindications, but does include them in the Warnings section. It is plausible that administering drotrecogin alfa (activated) in patients with clinical scenarios that may increase the risk of bleeding may lead to a higher frequency of bleeding episodes. Hence, the clinician should weigh the benefits of drotrecogin alfa (activated) carefully against the risks in patients with the following scenarios.

Warnings as noted in the manufacturer's information include the following:

$\square$ Concurrent therapy with heparin at dosages that increase the activated partial thromboplastin time to $\geq 1.5$ times the control ( $\geq 15 \mathrm{U} / \mathrm{kg} / \mathrm{hr}$ ).

$\square$ Initial platelet count $<30 \times 10^{3} / \mathrm{mm}^{3}$, even if the platelet count is increased after transfusions.

$\square$ Gastrointestinal bleeding within the past 6 weeks.

$\square$ International normalized ratio greater than 3.

$\square$ Administration of oral anticoagulants within the previous 7 days unless INR $<3$.

$\square$ Administration of aspirin $>650 \mathrm{mg} /$ day or other platel et inhibitors (e.g., clopidogrel, dipyridamole, ticlopidine) within the past 7 days.

$\square$ Administration of glycoprotein IIb-IIla inhibitors within the past 7 days.

$\square$ Administration of thrombolytics within the past 3 days (catheter clearance doses are not considered a warning).

$\square$ Ischemic stroke within the past 3 months.

$\square$ Intracranial arteriovenous malformation or aneurysm.

$\square$ Known bleeding diathesis.

$\square$ Chronic severe hepatic disease.

$\square$ Any other condition in which bleeding constitutes a significant hazard or would be particularly difficult to manage because of its location.

IV. In the PROWESS trial, patients were excluded for specific criteria, including a futile diagnosis, increased risk of bleeding, and a known hypercoagulable condition. However, these specific criteria are not listed in the Xigris manufacturer's information. Hence, the clinician should weigh carefully the benefits of drotrecogin alfa (activated) against the risks in patients with the following scenarios.

Exclusion criteria, as noted in the PROWESS trial:

$\square$ Age $<18$ years.

$\square$ Weight $>135 \mathrm{~kg}$ (these patients were excluded to ensure adequate supply of drotrecogin alfa [activated]).

$\square$ Surgery requiring general or spinal anesthesia within 12 hours before the infusion.

$\square$ Potential need for surgery during the infusion.

$\square$ Known hypercoagulable condition including the following:

$\square$ Resistance to activated protein C.

$\square$ Hereditary deficiency of protein C, protein S, or antithrombin III.

$\square$ Presence of anticardiolipin antibody.

$\square$ Presence of antiphospholipid antibody.

$\square$ Presence of lupus anticoagulant.

$\square$ Presence of homocystinemia.

$\square$ Documented or highly suspected deep vein thrombosis or pulmonary embolism within the past 3 months.

$\square$ Patient's family, physician, or both not in favor of aggressive treatment of patient, or presence of an advanced directive to withhold life-sustaining treatment.

$\square$ Patients not expected to survive 28 days because of an uncorrectable medical condition such as poorly controlled neoplasm or other end-stage disease.

$\square$ Moribund state in which death was perceived as imminent.

Human immunodeficiency virus infection in association with a last known CD4 count of $\leq 50 / \mathrm{mm}^{3}$.

$\square$ History of bone marrow, lung, liver, pancreas, or small-bowel transplantation.

$\square$ Chronic renal failure requiring hemodialysis or peritoneal dialysis.

$\square$ Acute pancreatitis with no established source of infection.

- Any of the following treatment regimens (in addition to the ones listed under warnings):

$\square$ Low-molecular-weight heparin at a higher dosage than recommended for prophylaxis within the previous 12 hours.

Antithrombin III at a dose of more than 10,000 U within the previous 12 hours.

$\square$ Protein $C$ administration within the previous 24 hours. 
Appendix 2. Drotrecogin alfa (activated) (Xigris) Reconstitution and Administration Guidelines

Stability

- The intravenous solution should be prepared immediately on reconstitution of drotrecogin alfa (activated) vials because they do not contain any antibacterial preservative.

- If the vial is not reconstituted immediately, it may be stored at room temperature at $15-30^{\circ} \mathrm{C}\left(59-86^{\circ} \mathrm{F}\right)$ but must be used within 3 hours.

- Saline solutions contain an unspecified amount of zinc that may chelate with drotrecogin alfa (activated), thus the stability of drotrecogin alfa (activated) intravenous solutions is limited. At room temperature, after the intravenous solution of drotrecogin alfa (activated) is prepared, administration must be completed within 14 hours.

- Drotrecogin alfa (activated) admixtures may be stored in a refrigerator at $2-8^{\circ} \mathrm{C}\left(36-46^{\circ} \mathrm{F}\right)$ for up to 12 hours. The total in-use time after drotrecogin alfa (activated) reconstitution and refrigeration (maximum of 12 hrs) and administration at room temperature should not exceed 24 hours.

- The infusion bag should be inspected visually for foam production before administration.

- Avoid exposing drotrecogin alfa (activated) solutions to heat or direct sunlight.

- Covering the infusion bag to protect from light is unnecessary. However, if the drotrecogin alfa (activated) solution will be exposed to direct sunlight, it should be covered with a brown bag or aluminum foil.

- Drotrecogin alfa (activated) is a glycoprotein of approximately 55-kD molecular weight; excessive agitation may denature the glycoprotein. Drotrecogin alfa (activated) infusion bags should be handled gently and should not be transported by means of mechanical delivery systems.

Dilution

- Preparation of drotrecogin alfa (activated) should take place with an aseptic technique.

- When using an intravenous infusion pump to administer the drug, the solution of reconstituted drotrecogin alfa (activated) is diluted with $0.9 \%$ sodium chloride injection (U nited States Pharmacopeia [USP]) to a final concentration of $100-200 \mu \mathrm{g} / \mathrm{ml}$. The stability of drotrecogin alfa (activated) solutions that are more dilute (e.g., due to adsorption to tubing) or concentrated (e.g., due to degradation) has not been studied; excessive dilution or concentration therefore is not recommended.

- When using a syringe pump to administer the drug, the solution of reconstituted drotrecogin alfa (activated) is diluted with $0.9 \%$ sodium chloride injection (USP) to a final concentration of $100-1000 \mu \mathrm{g} / \mathrm{ml}$. When administering drotrecogin alfa (activated) at concentrations less than approximately $5 \mathrm{ml} /$ hour, the infusion rate must be primed for approximately 15 minutes at a flow rate of approximately $5 \mathrm{ml} / \mathrm{hour}$.

Administration and Compatibility

- No compatibility studies have been completed with intravenous drugs that are administered routinely in a critical care setting. Hence, drotrecogin alfa (activated) should be administered by means of a dedicated intravenous line or a dedicated lumen of a multilumen central venous catheter.

- The only solutions that can be coadministered through the same line as that used for a drotrecogin alfa (activated) intravenous solution (e.g., a y-line) are $0.9 \%$ sodium chloride injection (USP), Ringer's lactate injection, dextrose, or dextrose and saline mixtures with up to $40 \mathrm{mEq} / \mathrm{L}$ of potassium chloride.

- The dedicated line or lumen may be used for other reasons before or after drotrecogin alfa (activated) infusion, if flushed with $30-60 \mathrm{ml}$ of $0.9 \%$ sodium chloride injection (USP), dextrose, or dextrose and saline mixtures.

- No incompatibilities have been observed between drotrecogin alfa (activated) and glass infusion bottles or infusion bags and syringes made of polyvinylchloride, polyethylene, polypropylene, or polyolefin.

Vial Reconstitution

Drotrecogin alfa (activated) 5-mg and 20-mg vials must be reconstituted with $2.5 \mathrm{ml}$ and $10 \mathrm{ml}$, respectively, of sterile water for injection (USP), resulting in a concentration of approximately $2 \mathrm{mg} / \mathrm{ml}$.

Step 1: Slowly add the corresponding amount of sterile water for injection (USP) to the vial and avoid shaking or inverting the vial.

Step 2: Gently swirl each vial until the powder is completely dissolved.

Infusion Bag Preparation

The reconstituted vials must be diluted further with $0.9 \%$ sodium chloride injection (USP), resulting in a final concentration of $100-200 \mu \mathrm{g} / \mathrm{ml}$. All doses require a $100-\mathrm{ml}$ intravenous infusion bag.

Step 1: Slowly withdraw the appropriate prescribed amount of the reconstituted drotrecogin alfa (activated) solution from the vial.

Step 2: Add the reconstituted drotrecogin alfa (activated) solution to a $100-\mathrm{ml}$ infusion bag of $0.9 \%$ sodium chloride injection (USP) by directing the stream to the side of the bag to minimize agitation of the solution.

Step 3: Gently invert the infusion bag to obtain a homogeneous solution.

Adapted from references 5 and 20. 
Appendix 3. Drotrecogin alfa (activated) (Xigris) Dosing Chart

The dosage of drotrecogin alfa (activated) for all adult patients is $24 \mu \mathrm{g} / \mathrm{kg} / \mathrm{hour}$ for 96 hours administered as a continuous infusion. The drotrecogin alfa (activated) dosage is based on actual body weight on the first day that therapy is started. The dosage should not be adjusted despite increases or decreases in body weight. The infusion rates listed below provide the appropriate dosage based on the corresponding weight and at a standard concentration of $200 \mu \mathrm{g} / \mathrm{ml}(20 \mathrm{mg} / 100 \mathrm{ml})$.

\begin{tabular}{cccccccc}
$\begin{array}{c}\text { Weight } \\
(\mathrm{kg})\end{array}$ & $\begin{array}{c}\text { Infusion Rate } \\
(\mathrm{ml} / \mathrm{hr})\end{array}$ & $\begin{array}{c}\text { Weight } \\
(\mathrm{kg})\end{array}$ & $\begin{array}{c}\text { Infusion Rate } \\
(\mathrm{ml} / \mathrm{hr})\end{array}$ & $\begin{array}{c}\text { Weight } \\
(\mathrm{kg})\end{array}$ & $\begin{array}{c}\text { Infusion Rate } \\
(\mathrm{ml} / \mathrm{hr})\end{array}$ & $\begin{array}{c}\text { Weight } \\
(\mathrm{kg})\end{array}$ & $\begin{array}{c}\text { Infusion Rate } \\
(\mathrm{ml} / \mathrm{hr})\end{array}$ \\
\hline 30 & 3.6 & 60 & 7.2 & 90 & 10.8 & 120 & 14.4 \\
31 & 3.7 & 61 & 7.3 & 91 & 10.9 & 121 & 14.5 \\
32 & 3.8 & 62 & 7.4 & 92 & 11.0 & 122 & 14.6 \\
33 & 4.0 & 63 & 7.6 & 93 & 11.2 & 123 & 14.8 \\
34 & 4.1 & 64 & 7.7 & 94 & 11.3 & 124 & 14.9 \\
35 & 4.2 & 65 & 7.8 & 95 & 11.4 & 125 & 15.0 \\
36 & 4.3 & 66 & 7.9 & 96 & 11.5 & 126 & 15.1 \\
37 & 4.4 & 67 & 8.0 & 97 & 11.6 & 127 & 15.2 \\
38 & 4.6 & 68 & 8.2 & 98 & 11.8 & 128 & 15.4 \\
39 & 4.7 & 69 & 8.3 & 99 & 11.9 & 129 & 15.5 \\
40 & 4.8 & 70 & 8.4 & 100 & 12.0 & 130 & 15.6 \\
41 & 4.9 & 71 & 8.5 & 101 & 12.1 & 131 & 15.7 \\
42 & 5.0 & 72 & 8.6 & 102 & 12.2 & 132 & 15.8 \\
43 & 5.2 & 73 & 8.8 & 103 & 12.4 & 133 & 16.0 \\
44 & 5.3 & 74 & 8.9 & 104 & 12.5 & 134 & 16.1 \\
45 & 5.4 & 75 & 9.0 & 105 & 12.6 & 135 & 16.2 \\
46 & 5.5 & 76 & 9.1 & 106 & 12.7 & & \\
47 & 5.6 & 77 & 9.2 & 107 & 12.8 & & \\
48 & 5.8 & 78 & 9.4 & 108 & 13.0 & & \\
49 & 5.9 & 79 & 9.5 & 109 & 13.1 & & \\
50 & 6.0 & 80 & 9.6 & 110 & 13.2 & & \\
51 & 6.1 & 81 & 9.7 & 111 & 13.3 & & \\
52 & 6.2 & 82 & 9.8 & 112 & 13.4 & & \\
53 & 6.4 & 83 & 10.0 & 113 & 13.6 & & \\
54 & 6.5 & 84 & 10.1 & 114 & 13.7 & & \\
55 & 6.6 & 85 & 10.2 & 115 & 13.8 & & \\
56 & 6.7 & 86 & 10.3 & 116 & 13.9 & & \\
57 & 6.8 & 87 & 10.4 & 117 & 14.0 & & \\
58 & 7.0 & 88 & 10.6 & 118 & 14.2 & & \\
59 & 7.1 & 89 & 10.7 & 119 & 14.3 & & \\
\hline
\end{tabular}

apublished data are not available relative to the dosing of drotrecogin alfa (activated) in patients weighing more than $135 \mathrm{~kg}$. Adapted from references 5 and 20. 